\title{
Correlates of Self-directed Behaviors in Captive Cercopithecus aethiops
}

\author{
João Rodrigo Daniel • António José dos Santos • \\ Luís Vicente
}

Received: 8 October 2007 / Accepted: 4 July 2008

(C) Springer Science + Business Media, LLC 2008

\begin{abstract}
Researchers have widely used self-directed behaviors (SDB) as a behavioral indicator of anxiety in nonhuman primates. We examined if SDB rates in captive vervets (Cercopithecus aethiops) were associated with 1) proximity to conspecifics in general, 2) relative dominance rank of proximity partners, and 3) postconflict situations. Subjects were members of a captive group of vervets at the Lisbon Zoo, Portugal. The group comprised 3 males and 7 females, which were focal sampled for $10.5 \mathrm{~h}$ each. Vervets did not engage in more SBD while in proximity of conspecifics than while alone, and individual SDB rates were not generally influenced by dominance ranks of neighbors. Yet, victims of conflicts significantly increased their SDB rates after agonistic episodes, which is consistent with the view that SDB rates are an index of anxiety in Cercopithecus aethiops.
\end{abstract}

Keywords dominance $\cdot$ postconflict anxiety $\cdot$ self-directed behavior $\cdot$ vervet

\section{Introduction}

In the ethological literature, researchers have associated displacement behaviors with situations that are frustrating, stressful, or that involve some kind of motivational conflict (Maestripieri et al. 1992; Spruijt et al. 1992; Troisi 2002). The most common displacement activities in nonhuman primates are related to body care maintenance, such as self-grooming and scratching (Troisi 2002), and are commonly labeled self-directed behaviors (SDB).

J. R. Daniel $(\bowtie) \cdot$ A. J. dos Santos

Unidade de Investigação em Psicologia Cognitiva do Desenvolvimento e da Educação- Instituto

Superior de Psicologia Aplicada, 1149-041 Lisboa, Portugal

e-mail: joaordaniel@gmail.com

L. Vicente

Centro de Biologia Ambiental- Faculdade de Ciências da Universidade de Lisboa,

1749-016 Lisboa, Portugal 
Several sources of physiological and pharmacological evidence support the link between SDB expression and anxiety (Crawley et al. 1985; Maestripieri et al. 1992; Ninan et al. 1982; Redmond and Huang 1979; Schino et al. 1991, 1996). The laboratory-based studies prompted nonexperimental, observational studies on emotional states of nonhuman primates over the last 2 decades. Results of the studies suggested that individual SDB rates tend to increase in postconflict periods and return to baseline levels after reconciliation between former opponents: Macaca fascicularis (Aureli 1997; Aureli and van Schaik 1991; Aureli et al. 1989; Das et al. 1998); M. fuscata fuscata (Kutsukake and Castles 2001); M. sylvanus (Aureli 1997); Papio anubis (Castles and Whiten 1998); and preschool children (Fujisawa et al. 2005). Aureli (Aureli 1997; Aureli and van Schaik 1991) suggested that after a conflict individuals become stressed as a result of 2 ambivalent motivations: 1) withdrawing for fear of renewed attacks and 2) approach to reconcile. They manifest their uncertainty via increased rates of SDB. Postconflict anxiety is expected to decrease after affiliative exchanges between former opponents (reconciliation) because the risk of renewed attacks is reduced.

Close proximity to dominant individuals is also a potential uncertain circumstance for some nonhuman primates (Macaca fascicularis: Pavani et al. 1991; Troisi and Schino 1987; Papio anubis: Castles et al. 1999), because their presence is expected to increase the risk of becoming a target of aggression.

We aimed to extend previous results on macaques and baboons by examining if SDB rates in captive vervets (Cercopithecus aethiops) correlate with 1) proximity to conspecifics in general, 2) relative dominance rank of proximity partners, and 3) postconflict situations.

de Vries and colleagues (2006) have recently proposed an operational measure of steepness, as a complementary feature of traditional linearity in dominance hierarchies. Via both measures, one can effectively describe hierarchies along the gradient between egalitarian (weakly linear and shallow) and despotic (linear and steep). By providing both measures, we allow future comparisons, to evaluate the extent to which the type of dominance hierarchy relates to SDB expression in the presence of group members.

There has been an increasing emphasis on the basic mechanisms animals use to make their social decisions (Aureli and Schaffner 2002). Primates are constantly confronted with situations in which the evaluation of the internal state of others is vital to make the decisions. If SDB reflect short-term anxiety, then it can provide information about how subjects perceive certain events.

\section{Materials and Methods}

\section{Subjects and Housing}

Subjects were members of a captive vervet group at the Lisbon Zoo, Portugal. They comprised 3 males ( 1 adult $>10$ yr and 2 subadults 4 yr) and 7 females (5 adults $>5 \mathrm{yr}$ and 2 juveniles 2 and $3 \mathrm{yr}$ ). None of the adults was born at the zoo, and they all entered the group at different times from diverse locations. Subadult males and juvenile females were all born at the zoo, but only the youngest female had her 
mother present at the onset of the study (however, available records did not identify which female is the mother).

Monkeys were housed in an octagonal outdoor enclosure of $c a .300 \mathrm{~m}^{3}$, with a partially open roof and a cement floor. It contains several wooden structures that provide shade and additional surface area for climbing and sitting. It also has 3 small shelters for sleeping and protection from the weather. Staff cleaned the enclosure daily, and the monkeys fed twice a day: a main meal in the morning and a supplement in the afternoon.

\section{Data Collection}

Daniel collected all data. Continuous focal sampling (Altmann 1974) began on March 2003 and concluded on July of the same year. Focal samples lasted 5 min, and we sampled each focal individual for $10.5 \mathrm{~h}$ (126 5-min samples), between $1000 \mathrm{~h}$ and $1800 \mathrm{~h}$, with no subject observed twice before all others were watched once.

SDB definitions are per Schino et al. (1988): 1) self-scratch: repeated movement of hand or foot during which the digits are drawn across the fur or skin; 2) selfgroom, picking through or slowly brushing aside one's own fur with one or both hands; 3) self-touch: other forms of manually touching the body, e.g., wiping eyes, placing hands in the mouth or inspecting feet; 4) body shake: shaking movement of the entire body, similar to that of a wet dog; and 5) yawn: brief gaping movement of the mouth (not recorded if accompanied by aggressive signals). Whenever we scored an SDB bout, we also recorded the identity of other individuals $\leq 2 \mathrm{~m}$ of the focal individual. We scored breaks in SDB lasting $>2 \mathrm{~s}$ or switches between forms of SDB as separate bouts.

During the focal sampling we also recorded the occurrence of approach/avoid interactions to derive the dominance matrix.

Definitions of aggressive interaction — stare, threaten, slap, push away, bite or chase (Fairbanks 1980; Hector et al. 1989; Raleigh and McGuire 1989)- occurred infrequently; therefore, we recorded them via all-occurrence sampling (Altmann 1974). Owing to housing size and observation conditions we are confident that we introduced no bias via all-occurrence sampling. Per de Waal and Yoshihara (1983), $10 \mathrm{~min}$ postconflict (PC), we initiated focal observations on the target (victim) of aggression whenever an aggressive exchange occurred. We stopped any ongoing focal sample observation at the point and initiated a new focal sample for the previous target after completing the postconflict observations. We recorded the identities of all individuals involved in the aggressive episode and the nature of their roles, i.e., victim, aggressor, supporters of either party. If conflict between former opponents reoccurred in $\leq 60 \mathrm{~s}$, we restarted the PC observation after the new interaction concluded. In PC periods, we recorded all affiliative and aggressive interactions involving the focal subject. Affiliative interactions include grooming, huddling, lip smacking, muzzle contact, genital inspection, and playing (Fairbanks 1980; Hector et al. 1989; Raleigh and McGuire 1989). We also recorded the focal subject's SDB. We conducted matched control (MC) focal observations of the same individual whenever possible, the next day at the same time. If the focal subject was involved in a conflict $5 \mathrm{~min}$ before a scheduled $\mathrm{MC}$, or if he was already in body 
contact with former opponent(s), we postponed the MC until all necessary conditions were met.

We independently took an additional 100 focal samples per subject, lasting $30 \mathrm{~s}$, normally at the conclusion of an observation day, to record the identity of each focal individual's proximity neighbors $(<2 \mathrm{~m})$, at the end of the 30 -s interval. Again, we observed no individual twice before watching all others once.

\section{Data Analysis}

We assessed individual dominance ranks via David's score (DS; David 1987, 1988), with the correction proposed by de Vries et al. (2006). Because the DS vary according to group size, we converted DS into a normalized DS (NormDS; de Vries et al. 2006). We also calculated linearity and steepness measures for the obtained dominance hierarchy (de Vries 1995; de Vries et al. 2006). Linearity and steepness are complementary structural measures, with linearity measuring the degree of transitivity, and steepness measuring the degree to which individuals differ from each other in winning dominance encounters (de Vries et al. 2006).

Next, for each focal subject we calculated the number of SDB bouts performed per min and the proportion of the bouts that were performed at $<2 \mathrm{~m}$ of other subjects. We then compared that proportion to the proportion of the independent proximity point samples in the same conditions, i.e., proportion of proximity focal samples in which the focal individual was $\leq 2 \mathrm{~m}$ of any other.

Subsequently, we followed the procedure of Castles et al. (1999), wherein $s$ is the number of SDB bouts shown by the focal subject, when individual $X$ was the only individual in proximity; $p$ equals the number of proximity point samples, in which $X$ was in the same conditions as above. For individual $X$, the focal subject's neighbor SDB rate equals $s / p$. For the 8 subjects that had higher- and lower-ranking partners, we compared each individual's mean SDB rate for his or her higher-ranking neighbors to his or her mean SDB rate for lower-ranking neighbors.

To determine whether SDB rates increased after conflicts, we compared PC SDB (overall) rates per min to mean MC SDB rates. We used mean values because we expected no significant deviation from a flat time course distribution. We analyzed only overall rates (all SDSs summed) because most of the individual SDSs, besides scratching, had very low occurrences.

We used exact $p$-values of test statistics, with $\alpha$-level for significance set at $5 \%$ (Mundry and Fischer 1998; Sokal and Rohlf 1995). Tests are 1-tailed unless stated otherwise.

\section{Results}

The dominance hierarchy obtained, via approach/avoid interactions, is significantly linear $\left(h^{\prime}=0.899, p<0.001,1000\right.$ randomizations $)$ and steep $(s=0.608, p<0.001$, 1000 randomizations).

Mean ( \pm SD) overall SDB rate among the 10 subjects is $0.523 \pm 0.171$ bouts $/ \mathrm{min}$ (self-scratch: $0.420 \pm 0.160$ bouts $/ \mathrm{min}$; self-groom: $0.036 \pm 0.037$ bouts $/ \mathrm{min}$; selftouch: $0.013 \pm 0.008$ bouts $/ \mathrm{min}$; body-shake: $0.007 \pm 0.006$ bouts $/ \mathrm{min}$; yawn: $0.046 \pm$ 
0.033 bouts $/ \mathrm{min}$ ). There is no relationship between vervet dominance rank and any SDB, excepting for self-groom where rates are higher for low-ranking individuals (Spearman rank correlation, $n=10$; overall: $r_{\mathrm{S}}=-0.382, p=0.138$; self-scratch: $r_{\mathrm{S}}=$ $-0.365, p=0.150$; self-groom: $r_{\mathrm{S}}=-0.742, p=0.007$; self-touch: $r_{\mathrm{S}}=-0.354, p=$ 0.158; body-shake: $r_{\mathrm{S}}=0.172, p=0.317$; yawn: $\left.r_{\mathrm{S}}=0.182, p=0.307\right)$.

All subjects had $\geq 1$ other individual $\leq 2 \mathrm{~m}$ on $63.5 \%( \pm 15.6 \%)$ of the proximity point samples. Looking at individual SDB rates as a function of whether or not there were other individuals $\leq 2 \mathrm{~m}$ showed that focal subjects did not engage in more SDB while in the presence of conspecifics. For some of the SDSs (yawn and overall; Fig. 1) the proportion of bouts recorded for each subject in proximity of others is even significantly smaller than expected versus the respective independent proximity samples (Wilcoxon signed-ranks, $n=10$; overall: $57.2 \pm 13.3 \%, T_{\mathrm{s}}=6, p=0.014$; selfscratch: $58.7 \pm 14.1 \%, T_{\mathrm{s}}=13, p=0.08$; self-groom: $48.5 \pm 29.1 \%, T_{\mathrm{s}}=14, p=0.097$; self-touch: $60.5 \pm 18.5 \%, T_{\mathrm{s}}=21, p=0.278$; body-shake: $66.5 \pm 40.1 \%, T_{\mathrm{s}}=24, p=$ 0.385 ; yawn: $54.7 \pm 16.2 \%, T_{\mathrm{s}}=1, p=0.002$ ).

Comparisons of individual mean SDB rates for higher-ranking neighbors to mean SDB rates for lower-ranking neighbors reveal no significant difference, with the exception of self-grooming, which is more common in the presence of high-ranking individuals (Wilcoxon signed-ranks, $n=8$; overall: $2.92 \pm 2.90$ vs. $1.83 \pm 0.928, T_{\mathrm{s}}=$ $13, p=0.273$; self-scratch: $2.32 \pm 2.42$ vs. $1.53 \pm 0.706, T_{\mathrm{s}}=13, p=0.273$, self-groom: $0.188 \pm 0.161$ vs. $0.075 \pm 0.143, T_{\mathrm{s}}=5, p=0.039$; self-touch: $0.081 \pm 0.098$ vs. $0.022 \pm$ $0.043, T_{\mathrm{s}}=7.5, p=0.164$; body-shake: $0.028 \pm 0.030$ vs. $0.031 \pm 0.054, T_{\mathrm{s}}=7.5, p=$ 0.562 ; yawn: $0.313 \pm 0.518$ vs. $0.168 \pm 0.202, T_{\mathrm{s}}=17, p=0.473$; Fig. 2).

Figure 3 contains SDB rates for 35 conflicts for which we had valid $\mathrm{PC}$ and $\mathrm{MC}$ observations. SDB rates for each minute during $\mathrm{PC}$ intervals are greater than $\mathrm{MC}$ average rate (PC: $0.923 \pm 0.287$ bouts/min; MC: $0.706 \pm 0.110$ bouts $/ \mathrm{min}$; Wilcoxon signed-ranks, $n=10, T_{\mathrm{s}}=9, p=0.03$ ). Only 1 of the 6 subjects for which we had PCMC observations had no higher average SDB rate in PC periods (Wilcoxon signedranks, $\left.n=6, T_{\mathrm{s}}=3, p=0.078\right)$.

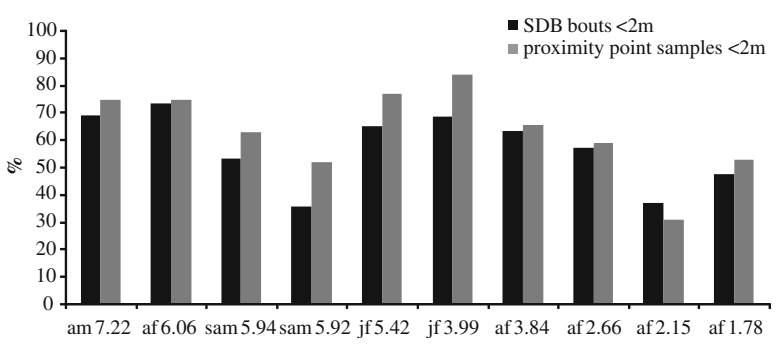

Fig. 1 Comparison of the proportion of SDB bouts performed at $<2 \mathrm{~m}$ of other subjects, with the proportion of independent proximity point samples in which the focal individual was at $<2 \mathrm{~m}$ of other subjects. Subjects are ordered according to their normalized David's score. am = adult male; af $=$ adult female; sam = subadult male; jf = juvenile female. 


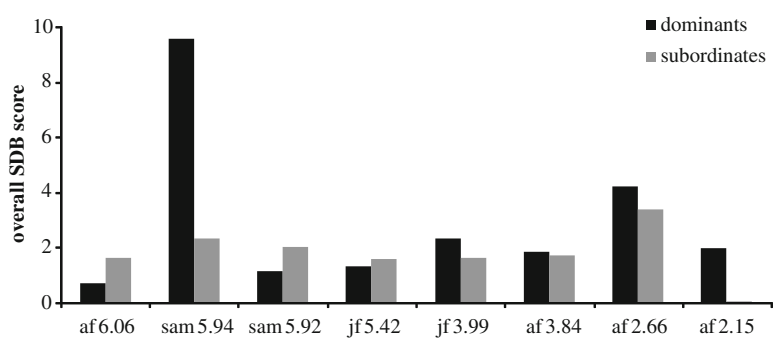

Fig. 2 Overall neighbor SDB score split for both dominants and subordinates. Order of individuals equals that of Fig. 1 top- and bottom-ranking individuals removed. am = adult male; af = adult female; sam = subadult male; $\mathrm{jf}=$ juvenile female.

\section{Discussion}

Generally speaking, vervets did not engage in more SBD while in proximity of conspecifics than while alone, which may be a reflection of the social system of vervets. Vervets have a high degree of cooperation for territorial defense, and as such, being alone may elicit more anxiety than the presence of a familiar individual. Castles et al. (1999) obtained similar results for olive baboons, suggesting that detachment from near neighbors is not a favorable condition because such situations may increase predation risk and separation from potential allies.

Vervets have a linear and steep dominance hierarchy; thus the presence of a dominant individual constitutes a greater danger of receiving aggression and consequently was expected to increase anxiety. Yet, contrary to our hypothesis, in the Lisbon vervets, SDB rates were not generally influenced by the presence of highranking individuals (with the exception of self-grooming). Schino et al. (1990) showed that well-established dominance relationships help to decrease the rate of self-directed behaviors. Though we have no long-term datum on the stability of the dominance hierarchy, if we consider that the dominance relationships were clearly defined and stable, they may account for why individuals belonging to a despotic group, i.e., with a linear and steep dominance hierarchy, show no consistent sign of anxiety in the presence of dominants. SDB expression is associated with potential uncertain situations; as such, group stability may allow vervets to predict their partners' behavior better.

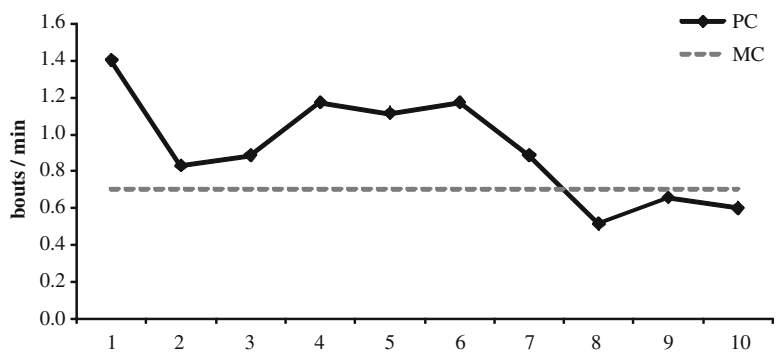

Fig. $3 \mathrm{SDB}$ (bouts/min) among all individuals during postconflict periods. 
Rank influence differed substantially from subject to subject (Fig. 2), suggesting the possibility of SDB varying according to other aspects of the relationship with the proximity partner besides differences in status (Castles et al. 1999).

Consistent with results reported for other Old World primates (Aureli 1997; Aureli and van Schaik 1991; Aureli et al. 1989; Castles and Whiten 1998; Das et al. 1998; Kutsukake and Castles 2001), victims of conflicts generally increased their SDB rates in the periods after agonistic events. However, the common postconflict anxiety pattern in Old World primates should not obscure the fact that differences in SDB rates, as well as in SDB temporal distribution, exist between species (Kutsukake and Castles 2001). The results still leave many open questions to be addressed in the future concerning natural conflict resolution in vervets.

In future observations, distinguishing the social context in which subjects were inserted when they performed SDB might prove to be very important because there is evidence that changes in the social setting influences SDB expression. For example, Manson and Perry (2000) found that female white-faced capuchins (Cebus capucinus) had higher self-grooming and scratching rates just before and after allogrooming bouts. A similar trend also occurred in rhesus macaques, which scratched themselves at higher rates in social contexts and just before and after changes in activity (Diezinger and Anderson 1986), and in male long-tailed macaques, whose SDB rates significantly increased during the $10 \mathrm{~s}$ after the end of allogrooming bouts initiated by females (Schino et al. 1988).

In conclusion, our results provide support for the notion that SDB is an index of anxiety in vervets; however, relationships between SDB and characteristics of dyadic relationships and contexts where they occur remains to be answered.

Acknowledgments We thank Dr. Fernando Paisana for permission to conduct the study at the Lisbon Zoological Garden. We also acknowledge all reviewers, especially Brian Vaughn, whose criticisms helped us improve previous versions of the paper. A PRODEPIII/2002 grant awarded to J. R. Daniel provided funding for the study.

\section{References}

Altmann, J. (1974). Observational study of behaviour: sampling methods. Behaviour, 49, 227-266. doi:10.1163/156853974X00534.

Aureli, F. (1997). Post-conflict anxiety in nonhuman primates: the mediating role of emotion in conflict resolution. Aggressive Behavior, 23, 315-328. doi:10.1002/(SICI)1098-2337(1997)23:5<315::AID$\mathrm{AB} 2>3.0 . \mathrm{CO} ; 2-\mathrm{H}$.

Aureli, F., \& Schaffner, C. M. (2002). Relationship assessment through emotional mediation. Behaviour, 139, 393-420. doi:10.1163/156853902760102726.

Aureli, F., \& van Schaik, C. P. (1991). Post-conflict behaviour in long-tailed macaques (Macaca fascicularis): II. Coping with uncertainty. Ethology, 89, 101-114.

Aureli, F., van Schaik, C. P., \& van Hooff, J. A. R. A. M. (1989). Functional aspects of reconciliation among captive long-tailed macaques (Macaca fascicularis). American Journal of Primatology, 19, 39-51. doi:10.1002/ajp.1350190105.

Castles, D. L., \& Whiten, A. (1998). Post-conflict behaviour of wild olive baboons: II. Stress and selfdirected behaviour. Ethology, 104, 148-160.

Castles, D. L., Whiten, A., \& Aureli, F. (1999). Social anxiety, relationships and self-directed behaviour among wild female baboons. Animal Behaviour, 58, 1207-1215. doi:10.1006/anbe.1999.1250. 
Crawley, J. N., Ninan, P. T., Pickar, D., Chrousos, G. P., Linnoila, M., Skolnick, P., et al. (1985). Neuropharmacological antagonism of the beta-carboline-induced "anxiety" response in rhesus monkeys. The Journal of Neuroscience, 5, 477-485.

Das, M., Penke, Z., \& van Hooff, J. A. R. A. M. (1998). Postconflict affiliation and stress-related behaviour of long-tailed macaque aggressors. International Journal of Primatology, 19, 53-71. doi:10.1023/A:1020354826422.

David, H. A. (1987). Ranking from unbalanced paired-comparison data. Biometrika, 74, 432-436. doi:10.1093/biomet/74.2.432.

David, H. A. (1988). The method of paired comparisons. London: C. Griffin.

de Vries, H. (1995). An improved test of linearity in dominance hierarchies containing unknown or tied relationships. Animal Behaviour, 50, 1375-1389. doi:10.1016/0003-3472(95)80053-0.

de Vries, H., Stevens, J. M. G., \& Vervaecke, H. (2006). Measuring and testing steepness of dominance hierarchies. Animal Behaviour, 71, 585-592. doi:10.1016/j.anbehav.2005.05.015.

de Waal, F. B. M., \& Yoshihara, D. (1983). Reconciliation and redirected affection in rhesus monkeys. Behaviour, 85, 224-241. doi:10.1163/156853983X00237.

Diezinger, F., \& Anderson, J. R. (1986). Starting from scratch: a first look at a 'displacement activity' in groupliving rhesus monkeys. American Journal of Primatology, 11, 117-124. doi:10.1002/ajp.1350110204.

Fairbanks, L. (1980). Relationships among adult females in captive vervet monkeys: testing a model of rank-related attractiveness. Animal Behaviour, 28, 853-859. doi:10.1016/S0003-3472(80)80145-X.

Fujisawa, K. K., Kutsukake, N., \& Toshikazu, H. (2005). Reconciliation pattern after aggression among Japanese preschool children. Aggressive Behavior, 31, 138-152. doi:10.1002/ab.20076.

Hector, A. C. K., Seyfarth, R. M., \& Raleigh, M. J. (1989). Male parental care, female choice and the effect of an audience in vervet monkeys. Animal Behaviour, 38, 262-271. doi:10.1016/S0003-3472(89)80088-0.

Kutsukake, N., \& Castles, L. D. (2001). Reconciliation and variation in post-conflict stress in Japanese macaques (Macaca fuscata fuscata). Animal Cognition, 4, 259-268. doi:10.1007/s10071-001-0119-2.

Maestripieri, D., Schino, G., Aureli, F., \& Troisi, A. (1992). A modest proposal: displacement activities as an indicator of emotions in primates. Animal Behaviour, 44, 967-979. doi:10.1016/S0003-3472(05)80592-5.

Manson, J. H., \& Perry, S. (2000). Correlates of self-directed behaviour in wild white-faced capuchins. Ethology, 106, 301-317. doi:10.1046/j.1439-0310.2000.00527.x.

Mundry, R., \& Fischer, J. (1998). Use of statistical programs for nonparametric tests of small samples often leads to incorrect P values: examples from Animal Behaviour. Animal Behaviour, 56, 256-259. doi:10.1006/anbe.1998.0756.

Ninan, P. T., Insel, T. M., Cohen, R. M., Cook, J. M., Skolnick, P., \& Paul, S. M. (1982). Benzodiazepine receptormediated experimental anxiety in primates. Science, 218, 1332-1334. doi:10.1126/science.6293059.

Pavani, S., Maestripieri, D., Schino, G., Turillazzi, P. G., \& Scucchi, S. (1991). Factors influencing scratching behaviour in long-tailed macaques (Macaca fascicularis). Folia Primatologica, 57, 34-38.

Raleigh, M. J., \& McGuire, M. T. (1989). Female influences on male dominance acquisition in captive vervet monkeys, Cercopithecus aethiops sabaeus. Animal Behaviour, 38, 59-67. doi:10.1016/S00033472(89)80065-X.

Redmond, D. E., \& Huang, Y. H. (1979). New evidence for a locus coeruleus-norephinephrine connection with anxiety. Life Sciences, 25, 2149-2162. doi:10.1016/0024-3205(79)90087-0.

Schino, G., Maestripieri, D., Scucchi, S., \& Turilazzi, P. G. (1990). Social tension in familiar and unfamiliar pairs of long tailed macaques. Behaviour, 113, 264-272. doi:10.1163/156853990X00518.

Schino, G., Perretta, G., Taglioni, A., Mónaco, V., \& Troisi, A. (1996). Primate displacement activities as an ethopharmacological model of anxiety. Anxiety, 2, 186-191. doi:10.1002/(SICI)1522-7154(1996) 2:4<186::AID-ANXI5>3.0.CO;2-M.

Schino, G., Scucchi, S., Maestripieri, D., \& Turillazzi, P. G. (1988). Allogrooming as a tension-reduction mechanism: A behavioural approach. American Journal of Primatology, 16, 43-50. doi:10.1002/ ajp.1350160106.

Schino, G., Troisi, A., Perretta, G., \& Mónaco, V. (1991). Measuring anxiety in nonhuman primates: Effects of lorazepam on macaque scratching. Pharmacology, Biochemistry, and Behavior, 38, 889891. doi:10.1016/0091-3057(91)90258-4.

Sokal, R. R., \& Rohlf, J. A. (1995). Biometry. New York: W. H. Freeman.

Spruijt, B. M., van Hooff, J. A. R. A. M., \& Gispen, W. H. (1992). Ethology and neurobiology of grooming behavior. Physiological Reviews, 72, 825-852.

Troisi, A. (2002). Displacement activities as a behavioral measure of stress in nonhuman primates and human subjects. Stress (Amsterdam, Netherlands), 5, 47-54. doi:10.1080/102538902900012378.

Troisi, A., \& Schino, G. (1987). Environmental and social influences on autogrooming behaviour in a captive group of Java monkeys. Behaviour, 100, 292-302. doi:10.1163/156853987X00161. 